\title{
O INTERNO E O EXTERNO NA EXPLICAÇÃO SOCIOLÓGICA: CONTINUIDADES E DESCONTINUIDADES DAS REALIDADES E DOS MODELOS ${ }^{1}$
}

Fernando Augusto Albuquerque Mourão ${ }^{l}$

Resumo: Publicado originalmente nos Anais de um Colóquio realizado na Associação Internacional de Sociólogos de Língua Francesa (Genebra, Suíça, 1993), este texto discute, na linha de Georges Balandier, a necessidade de um equilíbrio, no plano explicativo, entre fatores internos e fatores externos, no que concerne à análise das sociedades globais, bem como às dinâmicas das Relações Norte-Sul. Do ponto de vista teórico-metodológico, aponta os riscos e as armadilhas existentes no nível da realidade social, com reflexos sobre os modelos interpretativos dessas mesmas realidades. Este texto, embora datado, foi escrito e apresentado durante uma conjuntura internacional em que diversos regimes autoritários se transmutaram em democracias multipartidárias, e cediam às pressões por uma abertura crescente de seus mercados. Passado quase um quarto de século, verifica-se atualmente uma retomada das pressões liberalizantes, impostas a partir dos centros de poder financeiro e militar. Uma retomada da iniciativa, em reação aos discursos tecnicistas e impositivos, torna-se então mister para aqueles que não abandonam um imaginário utópico.

Palavras-chave: Explicação sociológica. Fator externo. Fator interno. Terceiro Mundo. Periferia e semiperiferia.

Abstract: Originally published in the Annals of a Colloquium held at the International Association of French-Speaking Sociologists (Geneva, Switzerland, 1993), this paper discusses, in the line of Georges Balandier, the need for an explanatory balance between internal factor and external factor, regarding the analysis of global societies, as well as the dynamics of North-South relations. From a theoreticalmethodological point of view, it points out the risks and pitfalls that exist at the level of social reality, with reflections on the interpretive models of these same realities. This text, although dated, was written and presented during an international conjuncture in which various authoritarian regimes were transmuted into multiparty democracies, and yielded to pressures for a growing openness of their markets. Almost a quarter of a century later, there has been a resumption of the liberalizing pressures imposed by the centers of financial and military power. A resumption of the initiative, in reaction to the technicist and impositional discourses, then becomes necessary for those who do not abandon a utopian imaginary.

Keywords: Sociological explanation. External factor. Internal factor. Third World. Periphery and semiperiphery.

\footnotetext{
${ }^{1}$ Versão original : MOURÃO, Fernando Augusto Albuquerque. L'interne et l'externe dans l'explication sociologique. HUTMACHER, Walo (Org.). Bulletin $n^{\circ} 7$ de l'Association Internationale des Sociologues de Langue Française. Genève: Service de la Recherche Sociologique, 1991, p. 79-88. Tradução de Bruno Anselmi Matangrano.

${ }^{1}$ Sociólogo, professor aposentado da Faculdade de Direito e do Departamento de Sociologia da Faculdade de Filosofia, Letras e Ciências Humanas da Universidade de São Paulo. Precursor, no Brasil, das sociologias do continente africano e das relações internacionais. Participou do projeto da publicação da Historia Geral da África, da UNESCO, como membro do Comitê Cientifico Internacional e do Bureau do projeto, como vice-presidente. Fundou o Centro de Estudos Africanos da USP. E-mail: faam@,usp.br.
} 
O paradigma de país moderno, capitalista ou socialista, torna-se hoje um objetivo a ser alcançado por todos no caminho que conduz ao progresso. Os países subdesenvolvidos só atingirão uma certa plenitude, que lhes permitirá participar do cenário internacional, depois de terem percorrido a experiência histórica de uns e de outros. A caracterização positiva ou negativa em termos de países modernos e tradicionais, segundo Cyril Black (1969, p. 3-31), é ainda uma das apresentações do problema em termos de dicotomia.

Esta série de correntes, seja neoclássica, seja neokeynesiana ou neomarxista, se constitui de excelentes formulações que, no entanto, na prática, se revelam escamoteadas, maltratadas e, o mais frequente, desconhecidas. A visão crítica, simplificadora da realidade, segundo a qual os países tradicionais acabam por ser simples objetos de disputa, com as vantagens da natureza heurística, prevê que estes devem percorrer a experiência histórica daqueles, o que não é tão simples.

Paralelamente a isso nascem outras correntes, como a "desconexão" de Samir Amin, tão discutida há alguns anos. Este conceito de relação de autarquia, uma opção de desenvolvimento autônomo que, na realidade, não traz um novo sistema adequado, nos conduz "a lugar nenhum, à utopia", segundo as palavras de Mário Murteira (1988, p. 163). De certa forma, é desesperador verificar a construção de paradigmas que, tendo doutrinado durante muitos anos, transformaram-se em correntes finalistas seguidas por adeptos fiéis que não nos conduziram efetivamente a um caminho seguro. Onde, portanto, encontra-se o erro: nos paradigmas ou nos processos de aplicação?

Uma boa parte dos trabalhos de sociologia que se referem ao Terceiro Mundo e a seus produtos nos conduzem não somente a esta confusão, mas também a ideias de natureza finalista que ainda não puderam resistir aos choques de processos, seja em nível internacional ou nacional.
Creio que, em uma fase de transmundialização, que Wallerstein chama de "economia-mundo", seja tradicionalmente centrada sobre o eixo atlântico ou sobre o eixo da bacia do Pacífico (atualmente designada como o futuro eixo possível), é quase impossível tratar ou admitir novas análises sociológicas do Terceiro Mundo sem levar em conta as transformações do paradigma internacional.

Apesar da importância do conceito de semiperiferia de Wallerstein, um conceito ainda por explorar amplamente, as transformações nascidas ao nível do paradigma das relações internacionais me parecem centrais para compreender os sentidos - na linha de compreensão de Georges Balandier - destas alterações em conexão com as alterações num nível mais interno, no nível de cada um dos atores do processo internacional. As continuidades e descontinuidades dão sentido a um processo dialético, um processo no qual este fator tempo emerge no plano das causalidades, das correlações.

Do ponto de vista cultural, temos assistido até agora, no plano das aparências, o registro de duas culturas: uma de natureza universal, abstrata, fruto de um pensamento do século XIX e bastante difundida com a multiplicação das vias de comunicação, e a outra, ou as outras, de natureza particular, as culturas particulares. A unidade cultural, de natureza etnocêntrica, começou a se destruir diante do aparecimento de culturas particulares que ganham uma importância não somente no plano das ideias, mas também como resultado de uma ação interna ou animadas de fora, por meio de ideias-chave deste fim de século que não é sempre muito moderno (MOURÃO, 1990, p. 151-155). O conceito de cultura universal, etnocêntrica, por oposição às culturas ditas menores ou também designadas como culturas pobres, enfrentou até aqui impactos consideráveis.

Em uma fase de desenvolvimento acelerado, é natural que nasça uma reelaboração do discurso técnico que não o opõe ao discurso utópico, a uma simples 
formulação maniqueísta. É natural que, com o tempo, se comece a considerar e a apresentar de maneira engajada os elementos fundamentais dos parâmetros culturais comuns, em um contexto de formulações culturais mais amplas que variam de acordo com os espaços. Partindo do princípio de que os conflitos são onipresentes na vida social e de uma certa maneira, fundamentais às gêneses histórico-sociais, é possível admitir que, se "a diversidade cultural, sob seus múltiplos aspectos, pode, muito frequentemente, dar margem aos conflitos enraizados sob formas hostis de etnocentrismo, é igualmente verdade que esta mesma diversidade pode ser trabalhada de modo a se transformar em instrumento de aproximação e não de desconfiança entre os povos.

O recurso aos processos de dinâmica cultural nos parece indispensável, pois não vemos direito o quanto dependemos disso para um conceito de progresso sem a variável cultural. As persistências ou as mudanças em nível cultural demonstram, no plano do discurso técnico, que "a relação tradição-mutação é redutora" (RIBEIRO, 1989, p. 97), como também concorda Adelino Torres. A análise dos processos de transformação e de mudança é mais que fundamental, é indispensável para a compreensão do processo que, devido às múltiplas sínteses que se seguem, nos confundem no nível das causas, conduzindo inclusive alguns autores a confundirem mutação com mudança, sobretudo em situações de causalidade dupla, isto é, causalidades provocadas pelo exterior e causalidades provocadas no nível da sociedade nacional.

Em relação aos países que estão transitando pelos estágios inferiores de desenvolvimento, os países desenvolvidos temem que suas mudanças possam conduzir a níveis de desordem no plano internacional, levando os países ditos "Modernos" a agirem sobre a revolução da modernização, de maneira a ajustar as necessidades dos primeiros em referência aos segundos. Convém ainda assinalar que, em fases nas quais o discurso técnico confronta as dificuldades de natureza financeira, entre outros, é comum recorrer ao discurso utópico como solução paliativa. A noção de progresso, por exemplo, passa a se aproximar mais de um dever ser, um julgamento de valor, do que da realidade propriamente dita, segundo a definição de René Hubert (1938).

Aparentemente, recorrer à utopia, ou melhor, à utilização do discurso utópico, sem ligação com o discurso técnico, nasce como uma possível solução em uma tentativa de evitar a ruptura do próprio discurso técnico, o que normalmente chega durante momentos de extensão de crises econômicas internacionais que desfavorecem o Terceiro Mundo.

No que diz respeito à subjetividade, é preciso considerar ainda que os países do Terceiro Mundo, situados até recentemente em uma posição de juízes dos países do Primeiro Mundo, estão passando a uma posição de acusados, já que são considerados não somente responsáveis por sua própria pobreza pela comunidade internacional, como ainda responsáveis também pela produção de drogas hoje amplamente consumidas no Primeiro Mundo.

Diante de um mundo que tende a se unir em grandes blocos - Europa Ocidental (Mercado Comum Europeu), EUA/Canadá e o México; o Japão e os chamados New Industrialised Countries (NICs); os países que formavam a antiga URSS -, a situação do Terceiro Mundo, sem nenhum mecanismo de ligação com os novos grandes blocos, determina uma situação de marginalidade. No plano psicológico, verificamos uma posição equivocada das elites do Primeiro Mundo, que passam, atualmente, de acusados a juízes, penalizando em seus julgamentos o Terceiro Mundo, que não consideram como membros confiáveis e entreveem como saída a responsabilidade e a interdependência global dos países do Primeiro Mundo. Esta seria, por sua vez, a única alternativa em resposta à anarquia e à fragmentação social do Terceiro Mundo, considerando o atraso e a pobreza como responsáveis pela instabilidade internacional, o que aumenta as assimetrias entre os dois mundos nos 
mais diversos níveis.

O esforço de redemocratização de vários países da América do Sul, tais como a Argentina e o Brasil (este, hoje, um dos maiores redutos eleitorais do Ocidente), não recebe atenção do Primeiro Mundo, o que faz aumentar a provável orientação dos capitais em direção aos países do Leste, hoje interessados em importar capitais sem apresentar as aparentes desvantagens do Terceiro Mundo.

A ideia de progresso, do ponto de vista interno, passa mais por uma concepção finalista, em que o "dever ser" aparece carregado de subjetividade, privilegiando o discurso utópico diante do discurso técnico, o que, de certa maneira, importa para o Primeiro Mundo em favor da crise econômica internacional, recompensando as correntes favoráveis a certa dominação e orientação do Terceiro Mundo, como o único caminho para pôr fim à anarquia econômico-financeira e que, em última análise, segundo certos autores de tratados, poderia levar a um desequilíbrio da paz. Isto quer dizer que o sistema internacional seria afetado pelos desequilíbrios e as desigualdades no plano dos subsistemas econômico (o desenvolvimento) e político (a ideologia), aumentando as tensões no nível do subsistema estratégico (o conflito e a segurança). De certo ponto de vista, isto nos faz retroceder ao século XIX, quando um equilíbrio precário face à canalização de uma parte das energias europeias favoreceu o movimento em direção ao estabelecimento de impérios coloniais.

Os tempos mudaram, mas a economiamundo tende a uma nova etapa, que reorganiza com dificuldade as noções de Primeiro e Segundo Mundos, conduzindo em direção ao que nomeamos como Nações Comerciais. Assim, reduz-se a capacidade do Terceiro Mundo de obter vantagens a seu favor por intermédio das fissuras do Primeiro Mundo, de modo que o núcleo de poder potencial do Terceiro Mundo diminui consideravelmente. Ideias centrais ligadas aos valores universais passam a ocupar o espaço, a ecologia, os direitos humanos, sem ser acompanhadas de um discurso técnico, com as perdas visíveis para os países do Terceiro Mundo. O desenvolvimento sai de cena, depois de ter ocupado espaço durante mais de trinta anos, ainda que com poucos resultados. $\mathrm{O}$ progresso é identificado com o avanço de um dos atores terreno do outro, enquanto o condomínio dos grandes tende a aumentar sua influência e seu poder. Torna-se cada vez mais difícil identificar o progresso.

O Terceiro Mundo perde momentaneamente suas vestes; o mundo que se lhe opõe, uma vez que o bipolarismo perdeu seu lugar, torna-se mais difuso, em um clima de disjunções entre o poder e a ordem internacional, no qual o poder dos países passa a se aproximar de uma função de Estado comercial, acompanhado de uma limitação de soberania.

As ideias de desenvolvimento nascem de maneira desarticulada interiormente, fortificadas pelo mito do progresso, mas descoladas da realidade que, no nível dos modelos, aparece escamoteada, alimentando planos de desenvolvimento a partir de dados bastante distorcidos da mesma realidade.

As racionalizações em torno do sistema social permanecem aquém da realidade. As análises sobre o continente africano continuam a preferir apresentar o mundo africano dividido por uma dualidade do tipo moderno/tradicional, uma visão reducionista da qual escapam importantes variáveis, como aquela do papel da burguesia comercial. Esta burguesia ligada aos comércios internacionais, como a da noz de cola, por exemplo, é sistematicamente esquecida, mesmo tendo um papel importante, seja do ponto de vista social, seja do ponto de vista econômico.

As distorções da realidade, em função da pretensão da racionalização através da planificação dos sistemas sociais, em função da não aceitação da ideia de certo dinamismo no nível das tradições, que aparece como tabu e está em via de ser superado em nome do progresso, levam na prática os paradigmas 
do desenvolvimento a certo impasse. O problema não é tratado somente no nível dos paradigmas, que, aliás, têm tido bastante importância, mas, sobretudo, no da dificuldade de sua adequação à realidade e principalmente porque uma boa parte de seus sucessores chegou a considerá-los de uma maneira finalista. Além disso, o sistema social real acabava "em uma forma racionalizadora, que lhe era exterior", segundo a análise de Adelino Torres (1988).

Enfim, pretendeu-se recobrir o modelo social com os paradigmas em nível da planificação que, aliás, não tinha tido sucesso enquanto paradigmas propriamente ditos. Não se pode negar, no entanto, a importância do papel da CEPAL na América Latina, enquanto que esta escola acabou por ser superada pelos novos acontecimentos ocorridos. Gravandose as relações entre os sistemas e os subsistemas regionais, a análise da economia-mundo deu provas de dinamismo no plano das relações intrassistêmicas, como no plano das antissistêmicas.

O conceito de Terceiro Mundo foi de repente atado ao subdesenvolvimento, que se desenvolveu a partir de uma visão entre fatos históricos e a relação entre as diferentes formas e modos de produção social, seja a partir da ótica em que o subdesenvolvimento é tratado como atraso natural, seja a partir dos paradigmas das correntes marxistas, que consideram o subdesenvolvimento como um produto contraditório do mundo desenvolvido. $\mathrm{O}$ conceito de Terceiro Mundo, de origem europeia, nasce para levar em consideração uma necessidade de classificação lógica das nações e colocar em evidência certas características comuns aos novos países. Mas a que se deve o fracasso da planificação sobre o continente africano e das correntes estruturalistas na América Latina?

Quanto a esta parte de insucesso, creio que ela não se deva somente a causas internas, mas também a causas externas de natureza política, a uma política de substituição de modelos de acordo com as numerosas orientações políticas que nasceram com o tempo.

No que diz respeito ao continente africano, ainda que se possa verificar as mesmas causas, creio que o problema seja mais complicado, pois parte de uma visão maniqueísta, opondo a tradição à modernidade, que deve ser alcançada a qualquer preço, partindo do princípio de que a tradição ou não é considerada, ou, no nível das políticas de planejamento, é até mesmo ultrapassada, como um elemento negativo para o progresso.

A mesma situação não acontece no Japão, onde a modernização levou em conta a tradição. Não houve ruptura. A cultura japonesa com seus aspectos específicos, foi, já há muito tempo, reconhecida, o que não é o caso da cultura da África, onde a ruptura, onde a aceitação de modelos culturais impostos pelo colonizador, nasce como condição essencial do progresso, que desconhece assim, ou que desqualifica, as culturas tradicionais. Mesmo nas formulações nacionalistas, a cultura africana tradicional não somente não é considerada, como também é fator de arcaísmo a ser vencido na marcha em direção ao progresso. A visão que a maior parte da literatura nos dá sobre este assunto é uma visão de uma sociedade africana dualista.

Até mesmo na fase de interdependências políticas, a maioria dos planejamentos e das políticas visa de preferência a um nivelamento de todos os segmentos sociais que compõem a população, por um parâmetro de modernidade. Não se leva em conta os aspectos contingentes dos planejamentos nem o fato de que, na prática, estas políticas conduziram a rupturas, a mutações que terminaram por marginalizar estes segmentos sociais com consequências desastrosas. Pois não somente não atingiram os objetivos almejados, como também estes segmentos estavam projetados em uma situação de desordem interna, como o mostra Georges Balandier.

Durante alguns séculos, o parâmetro foi 
a religião, tornando-se em seguida o conceito de civilização, e bem recentemente foi substituído pelo conceito de desenvolvimento, o que estabeleceu ao longo de todos estes séculos, a partir do século XVI, uma visão e uma prática dual. Religião, civilização e desenvolvimento são, portanto, parâmetros de referência. Mesmo tendo sido substituídos ao longo do tempo e do espaço colonial, permanecem na mesma ordem de dependência. No planejamento internacional, nós verificamos que as principais teorias de cada período, ainda que tenham mudado de linguagem de acordo com a realidade de cada tempo, mantêm a mesma postura dual, justificando em nome da religião, da civilização e do progresso uma situação de dominação em relação às periferias e semiperiferias. Não se deve tratar o problema a partir de uma visão "milenarista", que acaba por repetir os problemas similares e que tenderia a uma falsa visão de preservação. Trata-se, antes de tudo, de levar em conta a capacidade dinâmica e de adaptação dos segmentos tradicionais inseridos nas civilizações e nas culturas africanas, verificando o aparecimento de correlações funcionais na perspectiva de dois espaços e de dois tempos (ou ainda mais), pois, como afirma Georges Balandier, não podemos deixar de considerar os fatores culturais, raciais e o próprio fato colonial como fatores que intervieram no nível do processo social.

A sociologia poderá, sem dúvida, continuar a contribuir, ou mesmo ser retomada - não necessariamente no nível dos paradigmas de desenvolvimento que consideram a contribuição sociológica de alguns mais do que de outros, mas no plano da aplicação que constantemente se aproxima de um reducionismo de natureza mais econômica, de uma atitude finalista, de uma busca por progresso, escapando assim do aspecto contingente que tem fim em si mesmo. No que diz respeito ao tempo, é difícil conceber uma repetição do modelo, transposto de um espaço a outro, em termos de curto ou médio prazo. Pois é preciso ter em conta os resultados da interação entre fatores internos e externos (segundo as situações), que serão certamente vividos por várias gerações. Isso não agrada normalmente aos responsáveis pelos planos de desenvolvimento, preocupados com resultados imediatos. Adelino Torres até chama a atenção para o fato de que "ao longo das experiências de desenvolvimento africano destes últimos vinte e cinco anos, considerou-se sistematicamente que o que muda é importante e o que não muda é insignificante, ou descartável".

O processo de desenvolvimento, tema central para o continente africano, deve recorrer ao aprofundamento das categorias conceituais, aos conceitos e modos operacionais e às articulações entre a tradição e a realidade presente.

Um novo paradigma conceitual, ou paradigmas reformulados numa sociedade ou sociedades, onde o conflito nasce de forma universalizante, como normalidade intrínseca ao processo social, poderá contribuir para o aparecimento de metamorfoses e a sua inteligibilidade em um sistema internacional mantido por novos vetores, com ênfase sobre a maior velocidade do progresso científico e tecnológico. A pesquisa de grandes princípios, mais do que a de ideias plásticas, ultrapassa a possibilidade da formulação e da discussão de ideias, como já dizia Joseph Schumpeter, "pontos de vista" que tendem a enrijecer a relação.

Portanto, cabe à sociologia a tarefa de aprofundar as relações entre a concepção teórica e os fatos, que permanecem estritamente fiéis à realidade, através de um modelo de explicação universal, distanciado da miopia do Primeiro e do Terceiro Mundo.

Tradução de Bruno Anselmi Matangrano. 
Referências bibliográficas

BLACK, Cyril E. Challenges to an evolving legal order. In: FALK, Richard A.; BLACK, Cyril. E. (Eds.). The Future of the international legal order, Volume I. Princeton: Princeton University Press, 1969, p. 3-31.

HUBERT, René. Histoire de l'idée de progrès. In: Fondation Pour la Science. La notion de progrès devant la Science Actuelle: Sixième Semaine Internationale de Synthèse. Paris: Felix Alcan, 1938.

MOURÃO, Fernando Augusto Albuquerque. "O problema da(s) cultura(s) no limiar do ano 2000". In: Revista do patrimônio histórico e artístico nacional, Rio de Janeiro, número especial, p. 151-155, 1990.

MUTEIRA, Mário. Os Estados de língua portuguesa na economia mundial: ideologias e práticas do desenvolvimento. Lisboa: Presença, 1988.

RIBEIRO, Edgar Telles. Diplomacia cultural: seu papel na política externa brasileira. Brasília: IPRI, 1989.

TORRES, Adelino. Tradição e mutação na África contemporânea: o desenvolvimento econômico em causa. In: Estudos de economia, Lisboa, IX(1), p. 3-19, out./dez., 1988. 